\title{
ANALISIS KONTRASTIF BAHASA BUGIS DAN BAHASA INDONESIA DALAM BIDANG MORFOLOGI
}

\author{
Andi Fatimah Yunus \\ Fakultas Bahasa dan Sastra Universitas Negeri Makassar \\ Jalan Daeng Tata Raya, Kampus Parangtambung, Makassar \\ email: andifatimahyunus@gmail.com
}

\begin{abstract}
Analysis of Language Konstrastif Bugis and Indonesian in the Field of Morphology. This research is descriptive literature by using a comparative approach. The purpose of research is to describe the distinctive language and Indonesian Bugis in the field of morphology. The results of this study indicate that: (1) Differences in the pattern of morpheme Bugis language and Indonesian contained in: (a) a free morpheme, namely the free morpheme Bugis ends with vowels except e (pepet), while consonants not ending the free morpheme Bugis language except consonant / ng / and / q / (glottal). As for the free morpheme in Indonesian ends with all the vocal and consonant sounds except consonants / $\mathrm{q} / \& / \mathrm{x} / \mathrm{/} / \mathrm{b} /$ morpheme, ie the use of a prefix and suffix. (2) Differences in the pattern klitikasi Bugis and Indonesian languages are in use proklitik breath and hands. (3) The difference in the pattern of reduplication in language and Indonesian Bugis contained in reduplicated form the majority and reduplication berimbuhan. (4) The difference in the pattern of compounding and Indonesian Bugis language contained in the form of compound words in Bugis who first element consists of a basic word and the second element in the form of words berimbuhan (prefix ma-), while the Bugis language compound words the first and second elements in the form of basic words.
\end{abstract}

\begin{abstract}
Abstrak: Analisis Konstrastif Bahasa Bugis dan Bahasa Indonesia dalam Bidang Morfologi. Penelitian ini merupakan penelitian pustaka dengan menggunakan pendekatan deskriptif komparatif. Tujuan penelitian adalah untuk mendeskripsikan perbedaan bahasa Bugis dan bahasa Indonesia dalam bidang morfologi. Hasil penelitian ini menunjukkan bahwa: (1) Perbedaan pola morfem bahasa Bugis dan bahasa Indonesia terdapat pada: (a) morfem bebas, yaitu morfem bebas bahasa Bugis berakhir dengan bunyi vokal kecuali e (pepet), sedangkan konsonan tidak mengakhiri morfem bebas bahasa Bugis kecuali konsonan /ng/ dan /q/ (glotal). Adapun morfem bebas dalam bahasa Indonesia berakhir dengan semua bunyi vocal dan konsonan kecuali konsonan /q/ \& /x/, /b/ morfem terikat, yaitu penggunaan prefix dan sufiks. (2) Perbedaan pola klitikasi dalam bahasa Bugis dan bahasa Indonesia terdapat pada penggunaan proklitik na- dan ta-. (3) Perbedaan pola reduplikasi dalam bahasa Bugis dan bahasa Indonesia terdapat pada bentuk reduplikasi sebagian dan reduplikasi berimbuhan. (4) Perbedaan pola pemajemukan bahasa Bugis dan bahasa Indonesia terdapat pada bentuk kata majemuk dalam bahasa Bugis yang unsur pertama terdiri atas kata dasar dan unsur kedua berupa kata berimbuhan (berawalan $\mathrm{ma}$-), sedangkan kata majemuk bahasa Bugis unsur pertama dan kedua berupa kata dasar.
\end{abstract}

Kata kunci: analisis kontrastif, morfem, klitisasi, reduplikasi, pemajemukan

Masyarakat Indonesia pada umumnya tergolong masyarakat dwibahasa. Pada umumnya, mereka menguasai bahasa pertama (B1) bahasa daerah dan bahasa kedua (B2) bahasa Indonesia. Meskipun demikian, proses penguasaan kedua bahasa tersebut bervariasi sesuai dengan perkembangan pembangunan masyarakat Indonesia.

Apabila dua bahasa atau lebih digunakan secara bergantian oleh penutur yang sama, maka dapat dikatakan bahwa bahasa-bahasa tersebut dalam keadaan saling kontak (Suwito, 1983: 39).

Kontak bahasa dapat menimbulkan halhal yang menguntungkan bahasa masing-masing, yaitu penyerapan atau peminjaman yang memperkaya unsur-unsurnya. Akan tetapi, kontak bahasa dapat pula mengakibatkan hal-hal yang merugikan bahasa masing-masing. Kerugianini merupakan penyimpangan dari aturanaturan gramatika bahasa yang umum sehingga 
akan berakibat negatif kepada usaha menetapkan corak suatu bahasa baku atau bahasa standar dalam rangka pembinaan bahasa (Junus, 1997: 2).

Ahli-ahli linguistik sepakat bahwa orang-orang yang terlibat dalam penggunaan dua bahasa atau lebih mempunyai kecenderungan memindahkan unsur-unsur bahasa yang satu ke bahasa yang lain. Hal ini terjadi, baik pada bahasa pertama ke bahasa kedua, maupun sebaliknya (Parawansa, 1981: 5).

Terkait dengan masalah tersebut, Pranowo (1996: 4) mengatakan bahwa hambatan terbesar dalam proses menguasai bahasa kedua (B2) adalah tercampurnya sistem bahasa pertama (B1) dengan sistem bahasa kedua (B2).

Dalam pembelajaran bahasa kedua (bahasa Indonesia) di sekolah, siswa diharapkan dapat menguasai pola-pola serta kaidah-kaidah bahasa Indonesia dengan benar, namun pada kenyataannya tidak selalu demikian. Bahasa Indonesia siswa sering diwarnai oleh penyimpangan-penyimpangan yang disebabkan oleh dua faktor, yaitu (1) penutur bahasa pertama dalam hal ini siswa, terutama yang berdomisili di daerah lebih banyak menggunakan bahasa daerah daripada bahasa Indonesia dalam kegiatan komunikasinya sehingga kemungkinan besar penggunaan bahasa Indonesia siswa akan diwarnai oleh bahasa daerah, (2) siswa mengalami kesulitan dalam mempelajari bahasa Indonesia karena terdapat aturan-aturan bahasa Indonesia yang berbeda dengan bahasa daerahnya.

Perbedaan-perbedaan antara bahasa Indonesia dan bahasa daerah dapat diketahui dengan cara membandingkan kedua bahasa tersebut menggunakan analisis kontrastif. Berikut ini dilakukan penelitian analisis kontrastif bahasa Bugis dan bahasa Indonesia untuk mengetahui perbedaan pola morfem, klitisasi, reduplikasi, dan pemajemukan dalam bahasa Bugis dan bahasa Indonesia.

\section{METODE}

Penelitian ini merupakan penelitian pustaka dengan menggunakan pendekatan deskriptif-komparatif, yaitu membandingkan bentuk morfem, klitisasi, reduplikasi, dan pemajemukan bahasa Bugis dan bahasa Indonesia. Dari perbandingan tersebut, dapat diketahui perbedaan-perbedaan pola morfem, klitisasi, reduplikasi, dan pemajemukan bahasa Bugis dan bahasa Indonesia. Sumber data dalam penelitian ini adalah Budiistiharah dan bukubuku yang menyangkut morfologi bahasa Bugis dan morfologi bahasa Indonesia.

\section{HASIL PENELITIAN DAN PEMBAHASAN}

\section{Penyajian Hasil Analisis Data}

\section{Perbandingan Morfem dalam Bahasa Bugis dan Bahasa Indonesia}

Morfem dalam bahasa Bugis maupun dalam bahasa Indonesia terbagi atas dua, yaitu morfem bebas dan morfem terikat. Perbandingan morfem bebas dalam bahasa
Bugis dan bahasa Indonesia

$\begin{array}{ll}\text { Data } & \\ \text { BB } & \text { BI } \\ \text { hurupuq } & \text { huruf } \\ \text { arung } & \text { raja } \\ \text { dare } & \text { kera } \\ \text { aruki } & \text { tulis } \\ \text { kapéseq } & \text { raba } \\ \text { itai } & \text { lihat } \\ \text { lampé } & \text { panjang } \\ \text { cenning } & \text { manis } \\ \text { iyaq } & \text { saya } \\ \text { iko } & \text { engkau } \\ \text { idiq } & \text { engkau } \\ \text { patappulo } & \text { empat puluh } \\ \text { tellu } & \text { tiga } \\ \text { maéga } & \text { banyak }\end{array}$

Berdasarkan perbandingan di atas, tampak bahwa perbedaan morfem bebas bahasa Bugis dan bahasa Indonesia terletak pada bunyi terakhir, yaitu morfem bebas dalam bahasa Bugis berakhir dengan bunyi vokal kecuali e (pepet), sedangkan konsonan tidak mengakhiri morfem bebas bahasa Bugis kecuali konsonan /ng/ dan /q/ (glotal). Oleh karena itu, bahasa Bugis bersifat vokal atau vokalis. 


\begin{tabular}{|c|c|}
\hline \multicolumn{2}{|l|}{ Data } \\
\hline BB & BI \\
\hline mannasu & memasak \\
\hline maqbaca & membaca \\
\hline mangelli & membeli \\
\hline maqbulu & bergunung \\
\hline mallappo & bertumpuk \\
\hline maqguru & belajar \\
\hline macawa (mecawa) & tertawa \\
\hline maqdua & berdua \\
\hline massubbu & bersembunyi \\
\hline maccéq & mencat \\
\hline
\end{tabular}

Berdasarkan perbandingan di atas, tampak bahwa dalam bahasa Bugis dipergunakan morfem terikat $m a G-, m a q$-, dan maN- diikuti oleh kata dasar untuk membentuk kata kerja dan kata sifat, di samping itu dipergunakan juga morfem ikat $-i$ untuk menyatakan pelaku, sedangkan dalam bahasa Indonesia yang memiliki makna yang sama dengan bahasa Bugis selain dipergunakan morfem ikat meN-, juga dipergunakan morfem ikat $b e(r)$-, dan ter- untuk membentuk kata kerja dan kata sifat.

$\begin{array}{ll}\text { Data } & \\ \text { BB } & \text { BI } \\ \text { bacangeng } & \text { bacakan } \\ \text { okireng } & \text { tuliskan } \\ \text { sappareng } & \text { carikan } \\ \text { bengkungeng } & \text { cangkulkan } \\ \text { teddungeng } & \text { payungkan }\end{array}$

Berdasarkan perbandingan di atas, tampak bahwa struktur benefaktif dalam bahasa Bugis dan bahasa Indonesia berbeda. Bila dalam bahasa Bugis dipergunakan morfem ikat -eng yang berkombinasi dengan kata dasar, sedangkan dalam bahasa Indonesia dipergunakan morfem ikat $-k a n$.

\section{Data \\ BB BI \\ pateddek(i) keraskan (dia) \\ panok(i) turunkan \\ paenrek(i) naikkan}

Berdasarkan perbandingan di atas, tampak bahwa dalam bahasa Bugis, arti kausatif dinyatakan oleh bentuk $p a-$, sedangkan dalam bahasa Indonesia arti kausatif dinyatakan dengan imbuhan akhir-kan.

$\begin{array}{ll}\begin{array}{l}\text { Data } \\ \text { BB }\end{array} & \text { BI } \\ \text { sipeppéq } & \text { berpukulan } \\ \text { sigajang } & \text { bertikaran } \\ \text { sikalopaq } & \text { bergumul } \\ \text { sipaqdua } & \text { berduaan }\end{array}$

Berdasarkan di atas, tampak bahwa bahasa Bugis dan bahasa Indonesia mempunyai struktur tersendiri untuk menyatakan dwipihak atau simultan. Dalam bahasa Bugis dipergunakan morfem si- dan sipa- diikuti oleh kata dasar, sedangkan dalam bahasa Indonesia dipergunakan morfem ber- yang diikuti oleh dasar kata. Struktur ini boleh pula mendapat morfem ikat $-a n$.

\section{Perbandingan Klitisasi dalam Bahasa Bugis dan Bahasa Indonesia}

Data

BB

1. ubaca

kaubaca

kibaca kaubaca

nabaca dia baca

tabaca(i) kaubaca

2. utudang(i) kududuk (i)

mutudang(i) kaududuk(i)

kitudang(i) kaududuk(i)

natudang(i) dia $\operatorname{duduk}(\mathrm{i})$

tatudang(i) kaududuk(i)

talao kita pergi

tatudang kita duduk

Berdasarkan perbandingan di atas, tampak bahwa dalam bahasa Bugis terdapat lima morfem yang dapat berfungsi sebagai proklitik (kata ganti orang), yaitu $u$-, $m u-, k i-, n a-$, dan $t a-$. Struktur ini dapat juga mendapat morfem ikat $-i$ kalau dasar kata dari kata kerjanya adalah transitif, tetapi kalau dasar kata dari kata kerjanya adalah intransitif, maka tidak mendapat morfem ikat $-i$. Adapun bahasa Indonesia hanya terdapat dua morfem ikat yang dapat berfungsi sebagai proklitik (kata ganti orang), yaitu $k u$ dan kau-. Jadi, perbedaan bahasa Bugis dan bahasa Indonesia terletak pada penggunaan proklitik na- dalam bahasa Bugis, sedangkan 
dalam bahasa Indonesia tidak dalam bentuk proklitik.

$\mathrm{Na}$-merupakan bentuk proklitik dalam bahasa Bugis, sedangkan dalam bahasa Indonesia tidak berbentuk proklitik, tetapi keduanya menunjuk pada persona ketiga tunggal.

Adapun bentuk proklitik ta-dalam bahasa Bugis ada yang menunjuk pada persona kedua tunggal (kau-), ada pula yang menunjuk pada persona pertama jamak (kita). Bila menunjuk pada persona tunggal, maka dalam bahasa Indonesia jugaberbentuk proklitik. Namun bila yang dimaksud atau yang ditunjuk adalah persona pertama jamak, yaitu bentuk proklitik ta- 'kita' dalam bahasa Bugis, maka dalam bahasa Indonesia tidak berbentuk proklitik.

Begitu pula dengan bentuk proklitik $k i-$ dalam bahasa Bugis, bila menunjuk pada persona kedua tunggal (kau ), maka dalam bahasa Indonesia juga berbentuk proklitik, tetapi bila menunjuk pada persona pertama jamak (kami), maka dalam bahasa Indonesia tidak berbentuk proklitik.

\section{Data}

BB

Manukku

Gaukmu

Adammu

Inanna

amanna

alebbirenna

nabitta

passurotta

Berdasarkan perbandingan di atas, tampak bahwa dalam bahasa Bugis dan bahasa Indonesia digunakan juga morfem-morfem ikat yang berfungsi untuk menyatakan posesif. Untuk menyatakan relasi posesif digunakan morfemmorfem ikat yang berfungsi sebagai enklitik. Enklitik yang digunakan dalam bahasa Bugis untuk menyatakan posesif, yaitu $-k u,-m u$, $-n a$, dan - $t a$, sedangkan dalam bahasa Indonesia dinyatakan oleh $-k u$, $-m u$, dan -nya masingmasing untuk orang pertama, kedua, dan ketiga.

Enklitik - $t a$ hanya terdapat dalam bahasa Bugis. Sufiks ini menunjukkan relasi posesif orang kedua (hormat) dan dapat juga berarti relasi posesif orang pertama jamak.

\section{Perbandingan Reduplikasi dalam Bahasa Bugis dan Bahasa Indonesia}

$\begin{array}{ll}\text { Data } & \\ \text { BB } & \text { BI } \\ \text { balaq-balanca } & \text { belanja-belanja } \\ \text { kadeq-kadera } & \text { kursi-kursi } \\ \text { anynyaq-anynyarang } & \text { kuda-kuda } \\ \text { sabbaq-sabbaraq } & \text { sabar-sabar } \\ \text { balaq-balala } & \text { rakus-rakus } \\ \text { ella-ellau } & \text { minta-minta } \\ \text { engka-engkalinga } & \text { dengar-dengar } \\ \text { batto-battoa } & \text { besar-besar }\end{array}$

Berdasarkan perbandingan di atas, tampak bahwabentuk perulangan sebagian dalam bahasa Bugis berbentuk perulangan utuh dalam bahasa Indonesia yang bermakna sama dengan bentuk perulangan bahasa Bugis. Bentuk reduplikasi sebagian dalam bahasa Bugis ditemukan variasi bunyi seperti data di atas, yaitu ditemukan tambahan bunyi glotal $q$ sebagai variasi bunyi.

\section{Data \\ BB \\ mula-mulanna pertama-tama}

Berdasarkan perbandingan di atas, tampak bahwa dalam bahasa Bugis ditemukan bentuk reduplikasi sebagian menggunakan akhiran -na pada komponen kedua, sedangkan dalam bahasa Indonesia yang bermakna sama dengan bahasa Bugis tersebut, juga berbentuk perulangan sebagian dengan menggunakan awalan per-pada komponen pertama.

Data

BB

mallebu-lebu

BI

mapperi-peri

bulat-bulat

lekas-lekas

Berdasarkan perbandingan di atas, tampak bahwa reduplikasi berimbuhan dalam bahasa Bugis yang dalam bahasa Indonesia memiliki makna yang sama, berbentuk perulangan utuh dalam bahasa Indonesia.
Data
BB
sirotte-rotte
sipake-pake
sijelloq-jelloq
BI
kait-mengait
pakai-memakai
tunjuk-menunjuk 
Berdasarkan perbandingan di atas, tampak bahwa perulangan berimbuhan dengan menggunakan prefiks si- pada komponen pertama dalam bahasa Bugis, berbentuk perulangan berimbuhan menggunakan awalan me- pada komponen kedua dalam bahasa Indonesia yang memiliki makna yang sama.

\section{Data}

BB

\section{BI}

kaita-ita

ikut-ikutan

Berdasarkan perbandingan di atas, ditemukan bentuk perulangan berimbuhan dalam bahasa Bugis menggunakan awalan $k a$ - pada komponen pertama, sedangkan dalam bahasa Indonesia berbentuk perulangan berakhiran -an pada komponen kedua yang bermakna sama.

\section{Data}

BB

baiccuq-iccuq

\section{BI}

kecil-kecil

Berdasarkan perbandingan di atas, tampak bahwa dalam bahasa Bugis, kata dasar iccuq 'kecil' tidak memiliki makna perulangan iccuq-iccuq, tetapi baru bermakna bila berawalan $b a$ - pada komponen pertamanya, yaitu baiccuqiccuq yang sama maknanya dengan perulangan utuh 'kecil-kecil' dalam bahasa Indonesia.

\section{Data}

BB

BI

pakatauq-tauq

menakut-nakuti

Berdasarkan perbandingan di atas, tampak bahwabentuk perulangan dalam bahasa Bugis yang komponen pertamanya menggunakan awalan paka-, dalam bahasa Indonesia berbentuk perulangan yang komponen pertamanya berawalan $m e$ - dan komponen keduanya berakhiran $-i$.

Data

BB BI

asseqdi-seqding persatuan

accule-culeng permainan

akkampi-kampireng penjagaan

Berdasarkan perbandingan di atas, tampak bahwa bentuk perulangan berimbuhan dalam bahasa Bugis yang menggunakan konfiks a-... -eng berbeda bentuknya dengan bahasa Indonesia yang bermakna sama, yaitu tidak berbentuk perulangan tetapi berbentuk kata berimbuhan (berawalan dan berakhiran).

Perbandingan Kata Majemuk dalam Bahasa Bugis dan Bahasa Indonesia

Data

BB

to maraju

to matowa

bola doko

sao raja

Berdasarkan perbandingan di atas, ditemukan perbedaan kata majemuk bahasa Bugis dan bahasa Indonesia, yaitu kata majemuk bahasa Bugis unsur pertama terdiri atas kata dasar dan unsur kedua berupa kata berimbuhan (berawalan ma-), sedangkan kata majemuk bahasa Bugis unsur pertama dan kedua berupa kata dasar.

\section{PEMBAHASAN}

Perbandingan Pola Morfem dalam Bahasa Bugis dan Bahasa Indonesia

a. Perbandingan pola morfem bebas dalam bahasa Bugis dan bahasa Indonesia

Perbedaan pola bunyi akhir morfem bebas bahasa Bugis dan bahasa Indonesia.
BB semua vokal kecuali /e/ pepet hanya konsonan/q/ dan /ng/

\section{BI}

semua vokal

semua konsonan kecuali /q/ dan /x/ 
Pola di atas berdasarkan data di bawah ini:

$\begin{array}{ll}\text { BB } & \text { BI } \\ \text { hurupuq } & \text { huruf } \\ \text { arung } & \text { raja } \\ \text { aruki } & \text { tulis } \\ \text { kapéseq } & \text { raba } \\ \text { lampé } & \text { panjang } \\ \text { cenning } & \text { manis } \\ \text { iyaq } & \text { saya } \\ \text { iko } & \text { engkau } \\ \text { tellu } & \text { tiga } \\ \text { maéga } & \text { banyak }\end{array}$

Perbedaaan morfem bebas bahasa Bugis dan bahasa Indonesia, yang meliputi kata benda, kata kerja, kata sifat, kata ganti, dan kata bilangan terletak pada bunyi terakhirnya, yaitu semua morfem bebas dalam bahasa Bugis berakhir dengan bunyi vokal kecuali e (pepet), sedangkan konsonan tidak mengakhiri morfem bebas bahasa Bugis kecuali konsonan /ng/ dan /q/ (glotal), sedangkan semua morfem bebas dalam bahasa Indonesia berakhir dengan semua bunyi vokal dan konsonan kecuali konsonan /q/ $\operatorname{dan} / \mathrm{x} /$

b. Perbandingan pola morfem terikat dalam bahasa Bugis dan bahasa Indonesia

Adapun perbedaan pola penggunaan morfem terikat dalam BB dan BI adalah sebagai berikut.

Pola 1:

$$
\left\{\begin{array}{l}
m a G- \\
m a q- \\
m a N-
\end{array}\right\}+\left\{\begin{array}{l}
\mathrm{Kk} \\
\mathrm{Kb} \\
\mathrm{Ks} \\
\mathrm{Kbl}
\end{array}\right\}+(-\mathrm{i})
$$

Pola di atas berdasarkan data di bawah ini:

\begin{tabular}{l}
\multicolumn{1}{c}{ BB } \\
mannasu \\
maqbaca \\
mangelli \\
maqbulu \\
mallappo \\
maqguru \\
macawa (mecawa) \\
maqdua \\
massubbu \\
maccéq
\end{tabular}

BI memasak membaca membeli bergunung bertumpuk belajar tertawa berdua bersembunyi mencat

Morfem terikat $m a G-, m a q-$, dan maNdalam bahasa Bugis yang diikuti oleh kata dasar digunakan untuk membentuk kata kerja (verba) dan kata sifat (adjektiva), di samping itu dipergunakan juga morfem ikat $-i$ untuk menyatakan pelaku, sedangkan dalam bahasa Indonesia yang memilih makna yang sama dengan bahasa Bugis selain dipergunakan morfem ikat $m e N-$, juga dipergunakan morfem ikat $b e(r)$-, dan ter- untuk membentuk kata kerja (verba) dan kata sifat (adejktiva).



Pola 2 :

\section{BB BI}

$p a-+\mathrm{Kk} \mathrm{kk}+-k a n$

Pola di atas berdasarkan data di bawah ini:

$\begin{array}{ll}\text { BB } & \text { BI } \\ \text { pateddek(i) } & \text { keraskan (dia) } \\ \text { panok }(i) & \text { turunkan } \\ \text { paenrek }(i) & \text { naikkan }\end{array}$

Penggunaan awalan $p a$ - dalam bahasa Bugis pada kata kerja digunakan untuk menyatakan arti kausatif, sedangkan dalam bahasa Indonesia digunakan akhiran -kan untuk menyatakan arti kausatif.

Pola 3:

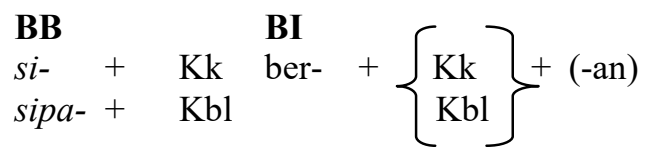

Pola di atas berdasarkan data di bawah ini:

BB

BI

sipeppéq berpukulan

sigajang bertikaran

sikalopaq bergumul

sipaqdua berduaan 
Dalam bahasa Bugis dipergunakan morfem si- dan sipa- diikuti oleh kata dasar untuk menyatakan dwipihak atau simultan, sedangkan dalam bahasa Indonesia dipergunakan morfem ber- yang diikuti oleh dasar kata. Struktur ini boleh pula mendapat morfem ikat an.

\section{Perbedaan Pola Klitisasi dalam Bahasa Bugis dan Bahasa Indonesia}

\begin{tabular}{ll} 
BB & \multicolumn{1}{c}{ BI } \\
$n a-+\mathrm{Kk}$ & dia $+\mathrm{Kk}$ \\
ta- $+\mathrm{Kk}$ & $\mathrm{kita}+\mathrm{Kk}$ \\
\multicolumn{2}{c}{ Pola di atas berdasarkan } \\
BB & \multicolumn{1}{c}{ BI } \\
nabaca & dia baca \\
natudang(i) & dia duduk(i) \\
talao & kita pergi \\
tatudang & kita duduk
\end{tabular}

Bentuk klitisasi dalam bahasa Bugis yang berbeda dengan bahasa Indonesia adalah penggunaan proklitik $n a$ - dan $t a$ - yang dalam bahasa Indonesia tidak berbentuk proklitik.

\section{Perbedaan Pola Klitisasi dalam Bahasa Bugis dan Bahasa Indonesia}

Berdasarkan hasil analisis data diperoleh beberapa perbedaan pola reduplikasi dalam bahasa Bugis dan bahasa Indonesia, yaitu:

Pola 1:

BB

\section{BI}

reduplikasi sebagian

reduplikasi utuh

Pola di atas berdasarkan data di bawah ini:

$\begin{array}{ll}\text { BB } & \text { BI } \\ \text { balaq-balanca } & \text { belanja-belanja } \\ \text { kadeq-kadera } & \text { kursi-kursi } \\ \text { anynyaq-anynyarang } & \text { kuda-kuda } \\ \text { sabbaq-sabbaraq } & \text { sabar-sabar } \\ \text { balaq-balala } & \text { rakus-rakus } \\ \text { élla-ellau } & \text { minta-minta } \\ \text { engka-angkalinga } & \text { dengar-dengar } \\ \text { batto-battoa } & \text { besar-besar }\end{array}$

Bentuk reduplikasi sebagian dalam bahasa Bugis ada yang berbentuk reduplikasi utuh dalam bahasa Indonesia yang bermakna sama. Bentuk reduplikasi sebagian dalam bahasa
Bugis ditemukan variasi bunyi, yaitu ditemukan tambahan bunyi glotal $q$ sebagai variasi bunyi.

Pola 2:

BB BI

$\mathrm{Ktw}+\mathrm{Ktw}+-n a \quad$ per $-\mathrm{Kbl}+\mathrm{Kbl}$

Pola di atas berdasarkan data di bawah ini :

BB BI

mula-mulanna pertama-tama

Dalam bahasa Bugis ditemukan bentuk reduplikasi sebagian menggunakan akhiran $-n a$ pada komponen kedua, sedangkan dalam bahasa Indonesia yang bermakna sama dengan bahasa Bugis tersebut juga berbentuk perulangan sebagian dengan menggunakan awalan per-pada komponen pertama.

Pola 3:

BB
$m a-$

Pola di atas berdasarkan data di bawah ini:

BB

BI

mallébu-lébbu bulat-bulat

mapperi-peri lekas-lekas

Ditemukan bentuk reduplikasi berimbuhan pada komponen pertama dalam bahasa Bugis, yaitu menggunakan awalan $\mathrm{ma}$ pada perulangan kata sifat, sedangkan dalam bahasa Indonesia yang bermakna yang sama berbentuk reduplikasi utuh.

Pola 4:

BB BI

$s i-{ }^{-} \mathrm{Kk} \quad \mathrm{Kk}+m e-+\mathrm{Kk}$

Pola di atas berdasarkan data di bawah ini:

BB

BI

sirotté-rotté kait-mengait

sipaké-paké pakai-memakai

sijelloq-jelloq tunjuk-menunjuk

Ditemukan bentuk reduplikasi berimbuhan pada komponen pertama dalam bahasa Bugis, yaitu menggunakan awalan sipada kata kerja, sedangkan dalam bahasa Indonesia yang bermakna yang sama berbentuk 
reduplikasi berimbuhan pada komponen kedua, yaitu menggunakan awalan me- pada perulangan kata kerja.

Pola 5:

$\begin{array}{ll}\text { BB } & \text { BI } \\ k a-+\mathrm{Kk}+\mathrm{Kk} & \mathrm{Kk}+\mathrm{Kk}+-a n\end{array}$

Pola di atas berdasarkan data di bawah ini:

\section{BB}

BI

kaita-ita

ikut-ikutan

Ditemukan dalam bahasa Bugis, bentuk perulangan yang komponen pertamanya berawalan ke-, sedangkan dalam bahasa Indonesia yang bermakna sama komponen keduanya yang berakhiran -an .

\section{Pola 6:}

$\begin{array}{ll}\text { BB } & \text { BI } \\ b a-+K s+K s & \mathrm{Ks}+\mathrm{Ks}\end{array}$

Pola di atas berdasarkan data di bawah ini :

\section{BB}

BI

baiccuq-iccuq kecil-kecil

Dalam bahasa Bugis tidak memiliki makna perulangan iccuq-iccuq, baru memiliki makna bila berimbuhan komponen pertamanya, yaitu baiccuq-iccuq yang sama maknanya dengan perulangan murni dalam bahasa Indonesia "kecil-kecil" (tidak berimbuhan).

Pola 7:

$$
\begin{aligned}
& \text { BB } \\
& \text { paka- }+\mathrm{Ks}+\mathrm{Ks} \quad \begin{array}{l}
\text { BI } \\
m e-
\end{array}+\mathrm{Ks}+\mathrm{Ks}-i
\end{aligned}
$$

Pola di atas berdasarkan data di bawah ini:

\section{BB}

BI

pakatauq-tauq menakut-nakuti

Pada bentuk perulangan bahasa Bugis ditemukan komponen pertamanya berawalan paka- yang bermakna sama dengan bentuk perulangan bahasa Indonesia yang komponen pertamanya berawalan me- dan komponen keduanya berakhiran $-i$.

Pola 8:

BB

BI

reduplikasi berimbuhan kata berimbuhan

Pola di atas berdasarkan data di bawah

ini:

BB

asseqdi-seqding

acculéq-culéng

akkampi-kampireng

Bentuk perulangan berimbuhan dalam bahasa Bugis yang menggunakan konfiks $a-\ldots$ eng berbeda dengan bahasa Indonesia yang bermakna sama, yaitu tidak berbentuk perulangan tetapi berbentuk kata berimbuhan (berawalan dan berakhiran).

\section{Perbedaan Pola Pemajemukan dalam Bahasa Bugis dan Bahasa Indonesia}

BB

$\mathrm{Kb}+m a-+\mathrm{Kb}$

BI

$\mathrm{Kb}+\mathrm{Kb}$

Pola di atas berdasarkan data di bawah ini:

BB

to maraja

(pembesar)

to matowa

bapak)

Pada perbandingan kata majemuk di atas, ditemukan pula perbedaan kata majemuk dalam bahasa Bugis dan bahasa Indonesia, yaitu kata majemuk bahasa Bugis unsur pertama terdiri atas kata dasar dan unsur kedua berupa kata berimbuhan (berawalan $m a$-), sedangkan kata majemuk bahasa Bugis unsur pertama dan kedua berupa kata dasar.

\section{KESIMPULAN}

Perbedaan pola morfem bahasa Bugis dan bahasa Indonesia terdapat pada: (a) morfem bebas, yaitu morfem bebas bahasa Bugis berakhir dengan bunyi vokal kecuali e (pepet), sedangkan konsonan tidak mengakhiri morfem bebas bahasa Bugis kecuali konsonan /ng/ dan /q/ (glotal). Adapun morfem bebas dalam bahasa Indonesia berakhir dengan semua bunyi vokal 
dan konsonan kecuali konsonan /q/ \& /x/, /b/ morfem terikat, yaitu penggunaan prefiks dan sufiks.

Adapun perbedaan pola klitikasi dalam bahasa Bugis dan bahasa Indonesia terdapat pada penggunaan proklitik $n a$ - dan $t a$-, sedangkan perbedaan pola reduplikasi dalam bahasa Bugis dan bahasa Indonesia terdapat pada bentuk

\section{DAFTAR PUSTAKA}

Junus, A. M. 1997. "Interferensi Morfologi Bahasa Bugis dalam Penggunaan Bahasa IndonesiaTulis Murid Sekolah Dasar yang Berbahasa Pertama Bugis di Kabupaten Wajo". Tesis. Ujung Pandang: Universitas Hasanuddin.

Junus, A. M. 2004. Morfologi Bahasa Bugis. Makassar. Badan Penerbit UNM.

Parawansa, Paturungi 1981. "Kajian Interferensi Morfologi pada Dwibahasawan Anak Murid Sekolah Dasar di Daerah Kabupaten Gowa Provinsi Sulawesi Selatan". Disertasi. Malang: IKIP Malang. reduplikasi sebagian dan reduplikasi berimbuhan.

Perbedaan pola pemajemukan bahasa Bugis dan bahasa Indonesia terdapat pada bentuk kata majemuk dalam bahasa Bugis yang unsur pertama terdiri atas kata dasar dan unsur kedua berupa kata berimbuhan (berawalan $m a-$ ), sedangkan kata majemuk bahasa Bugis unsur pertama dan kedua berupa kata dasar.

Pranowo. 1996. Analisis Pengajaran Bahasa. Yogyakarta: Gadjah Mada University Press.

Ramlan, M. 1987. Morfologi: Suatu kajian Deskriptif. Yogyakarta: CV Karyono.

Said, D. M., M. Ide dkk. 1979. Morfologi dan Sintaksis Bahasa Bugis. Jakarta: Departemen Pendidikan dan Kebudayaan.

Salim, Muhammad. 1993. Budiistiharah:Transliterasi dan Terjemah Lontarak. Ujung Pandang: Departemen Pendidikan dan Kebudayaan.

Suwito, 1983. Pengantar Awal Sosiolinguistik: Teori dan Problema. Surakarta: Henary Offset. 